Article

\title{
Forecasting Solar Power Using Hybrid Firefly and Particle Swarm Optimization (HFPSO) for Optimizing the Parameters in a Wavelet Transform-Adaptive Neuro Fuzzy Inference System (WT-ANFIS)
}

\author{
Nor Azliana Abdullah ${ }^{1}$, Nasrudin Abd Rahim ${ }^{1, *}$, , Chin Kim Gan ${ }^{2}$ and Noriah Nor Adzman ${ }^{1}$ \\ 1 Higher Institution Centre of Excellence (HICoE), UM Power Energy Dedicated Advanced \\ Centre (UMPEDAC), Level 4, Wisma R\&D, University of Malaya, Jalan Pantai Baharu, \\ Kuala Lumpur 59990, Malaysia \\ 2 Faculty of Electrical Engineering, Universiti Teknikal Malaysia Melaka (UTeM), Jalan Hang Tuah Jaya, \\ Durian Tunggal 76100, Melaka, Malaysia \\ * Correspondence: nasrudin@um.edu.my; Tel.: +60-322-463-246
}

Received: 20 June 2019; Accepted: 15 July 2019; Published: 7 August 2019

check for updates

\begin{abstract}
Solar power generation deals with uncertainty and intermittency issues that lead to some difficulties in controlling the whole grid system due to imbalanced power production and power demand. The forecasting of solar power is an effort in securing the integration of renewable energy into the grid. This work proposes a forecasting model called WT-ANFIS-HFPSO which combines the wavelet transform (WT), adaptive neuro-fuzzy inference system (ANFIS) and hybrid firefly and particle swarm optimization algorithm (HFPSO). In the proposed work, the WT model is used to eliminate the noise in the meteorological data and solar power data whereby the ANFIS is functioning as the forecasting model of the hourly solar power data. The HFPSO is the hybridization of the firefly (FF) and particle swarm optimization (PSO) algorithm, which is employed in optimizing the premise parameters of the ANFIS to increase the accuracy of the model. The results obtained from WT-ANFIS-HFPSO are then compared with several other forecasting strategies. From the comparative analysis, the WT-ANFIS-HFPSO showed superior performance in terms of statistical error analysis, confirming its reliability as an excellent forecaster of hourly solar power data.
\end{abstract}

Keywords: adaptive neuro-fuzzy inference system; firefly; forecasting; hybrid firefly and particle swarm optimization; particle swarm optimization; photovoltaic; wavelet transform

\section{Introduction}

Global warming is a modern crisis due to the vast consumption of fossil fuels for the generation of electricity. Therefore, renewable energy resources are a potential solution to this problem in reducing the amount of carbon dioxide $\left(\mathrm{CO}_{2}\right)$ emissions as well as keeping the pollution level under control [1]. Solar energy is one of the most promising energy resources due to its wide-ranging benefits of being a clean, cost-free and abundant source [2]. For these reasons, the use of solar energy in electric power generation is in demand as part of efforts to address these environmental issues.

However, the production of output power by photovoltaic (PV) panels is unreliable and stochastic as it is influenced by various environmental factors such as surrounding temperature, solar radiation, shading, humidity and wind speed. These are among the challenges that electric grid operators have to face in order to manage the electricity supply system efficiently [3]. To overcome these challenges, several strategies have been developed to balance consumption and generation of electric power. 
Forecasting of demand on the loads in the short term is one of the strategies to improve operation stability of power systems [4]. The other strategy, which is addressed in this paper, consists of power forecasting using renewable energy resources.

Solar power forecasting is essential for energy trading companies and dispatching centres of power networks to make accurate decisions on specific vital issues such as scheduling arrangements and operational control of the power system [5]. On top of that, a precise solar power forecasting improves the reliability and power quality of the overall power system [6].

Generally, solar power forecasting can be classified as direct and indirect forecasting. Direct forecasting predicts solar power data as the model output. On the other hand, indirect forecasting generates the forecasted values of solar radiation. Consequently, the forecasted values of solar radiation are being utilized in PV performance models for deriving solar power production [7]. In the solar power forecasting field, there are two main categories of forecasting methods, namely, physical methods and statistical methods. The physical methods forecast the factors (solar radiation or temperature) that directly influence the production of solar power. Then, the predicted value of solar power is obtained by utilising the forecast result as the input of the physical methods [8]. Otherwise, the statistical methods are built based on historical data and machine learning algorithms to directly forecast solar power without using any physical methods [9].

In literature, researchers have proposed different types of machine learning algorithms for forecasting purposes. The function of the machine learning algorithms is to find the relationship between the input and output values [9]. Multi-layer perceptron (MLP) is a type of artificial neural network (ANN) approach which is a highly competitive method for solar energy forecasting. The comparison studies between the MLP model with other forecasting strategies were done by previous works. Nandi et al. compared the MLP model with the Klucher and isotropic sky models [10]. The outcomes showed that there was a good agreement between the forecasted values and actual values of solar radiation, which represents the outstanding performance of the MLP model. Another work was made by Abuella et al. for solar power forecasting and the results indicated the superiority of MLP when compared with the multiple linear regression (MLR) and persistence model [11].

Awad et al. utilized a K clustering algorithm to determine the center of the activation function for the radial basis function neural network (RBFNN) model [12]. Li et al. employed the RBFNN as a forecasting model of PV power in China, and the results showed a lower error percentage during normal and sudden weather changes, showing the ability of the proposed RBFNN to achieve a higher forecasting accuracy [13].

The adaptive neuro-fuzzy inference system (ANFIS) technique was applied by Olatomiwa et al. to simulate solar radiation and the result described a better performance of ANFIS when compared with the persistence model, support vector regression (SVR) model and ANN model [14]. Muhammad et al. applied the ANFIS and Autoregressive moving average with exogenous input (ARMAX) model to forecast the global solar radiation (GSR) in Nigeria [15]. This work verified the better performance of the ANFIS than the ARMAX in achieving a mean absolute percentage error (MAPE) value of less than $10 \%$ for the training process and testing process. Sumithira et al. employed the ANFIS model to predict monthly solar radiation for 31 districts in Tamil Nadu, India and the proposed model demonstrated a better result when compared with other methods used by previous works [16].

A solar radiation forecasting model that is based on the support vector machine (SVM) was proposed by Ramli et al. [17]. Improved forecasting accuracy of the proposed model was obtained by comparing the SVM with the ANN model. Ekici et al. employed a least squares support vector machine (LS-SVM) to predict solar insolation on daily basis, by considering the number of days, daily mean temperature, daily maximum temperature, sunshine duration and solar insolation of the previous day as inputs of the developed model [18]. An LS-SVM model was also developed by Zeng et al. for short-term solar power prediction by employing two-dimensional (2D) transmissivity and meteorological variables (sky cover, relative humidity and wind speed) as the model inputs [19]. The 
proposed model was revealed to have outperformed the autoregressive (AR) and RBFNN models in terms of forecasting accuracy.

There are some studies that incorporate a forecasting model with an optimization algorithm. Mohandes et al. proposed a hybrid model of an ANN and particle swarm optimization (PSO) to estimate the monthly mean daily GSR [20]. Similarly, Ibrahim et al. [21] and Olatomiwa et al. [22] applied a random forest-firefly algorithm and an SVM-firefly algorithm, respectively, for GSR prediction. All of the above-mentioned works of literature which combine a forecasting model with an optimization algorithm have given better accuracy during forecasting. However, those hybrid methods do not consider the data filtration technique used to eliminate noise in the data.

The existence of noise in data has degraded the accuracy of a forecasting model for prediction. Due to this, many researchers have resorted to the use of a denoising technique to eliminate noise in time series data. Catalao et al. combined a wavelet transform (WT) and an ANN for wind power forecasting, where the WT was utilized as a denoising tool of the data [23]. Likewise, Lyu et al. applied a WT in filtering the noise of solar irradiance forecasting [24]. The existence of noise causes the data to become non-stationary, leading to the wrong model coefficient. As a result, the forecasting process becomes less accurate. By using a denoising tool, the data can be stationary and consequently improve the prediction accuracy of the model. In the literature from Catalao et al. [23] and Lyu et al. [24], only the denoising part was considered. The weaknesses of the ANN, such as the manual setting of parameters and local minima realization, were not mitigated. In fact, these weaknesses will reduce the predictive strength of hybrid models.

To the best of the author's knowledge, the available publications focused on solar power forecasting under the following techniques:

(1) Incorporating a forecasting model with an optimization algorithm [20-22].

(2) Combining a denoising technique with a forecasting model [23,24].

(3) Integrating a denoising technique with a forecasting model and a single optimization algorithm $[5,25]$.

According to the following assumptions, this paper takes into account a solar power forecasting model that utilizes the WT as a denoising technique, the ANFIS model as a forecasting tool and the hybrid firefly particle swarm optimization (HFPSO) as a hybrid optimization algorithm. The accuracy of the proposed model (WT-ANFIS-HFPSO) is compared with several forecasting strategies, namely, MLP, RBFNN, ANFIS, WT combined with MLP (WT-MLP), WT combined with RBFNN (WT-RBFNN), WT combined with ANFIS (WT-ANFIS), WT-ANFIS combined with PSO algorithm (WT-ANFIS-PSO) and WT-ANFIS combined with the firefly (FF) algorithm (WT-ANFIS-FF). The outcomes of the proposed model of the WT-ANFIS-HFPSO have shown excellent and accurate results for solar power forecasting.

The paper is organized as follows: Section 2 presents the procedures of forecasting strategy that elaborates the data analysis of this work and describes the detailed methodology of the proposed WT-ANFIS-HFPSO. The five performance metrics that were used to evaluate the accuracy of the forecasting models are discussed in Section 3. The simulation results of the developed work and the accuracy comparison of the proposed work with other eight forecasting strategies are explained in Section 4 . The concluding remark of this study is shown in Section 5.

\section{The Procedures of Forecasting Strategy}

This work proposes the WT-ANFIS-HFPSO as a model to forecast future solar power data. As for the first part of this work, the WT approach is utilized to eliminate the noise in meteorological data and solar power data that is collected from the Universiti Teknikal Malaysia Melaka (UTeM). The existence of noise has caused the data to be non-stationary and led to inaccurate forecasting. By utilizing WT as the noise elimination tool, the accuracy of a forecasting model can be improved. In the second part of this work, the denoised data is introduced to the ANFIS model where the HFPSO algorithm is employed to optimize the premise parameters of the ANFIS. The HFPSO algorithm refers to the merging of two optimization algorithms (FF and PSO) into a single framework. The hybridization 
mitigates the disadvantages and brings out the advantages of both algorithms to yield more favourable model performance. The schemes of the forecasting strategy of the WT-ANFIS-HFPSO can be depicted in the flowchart as shown in Figure 1 where all of the forecasting strategies are implemented in MATLAB R2015a language.

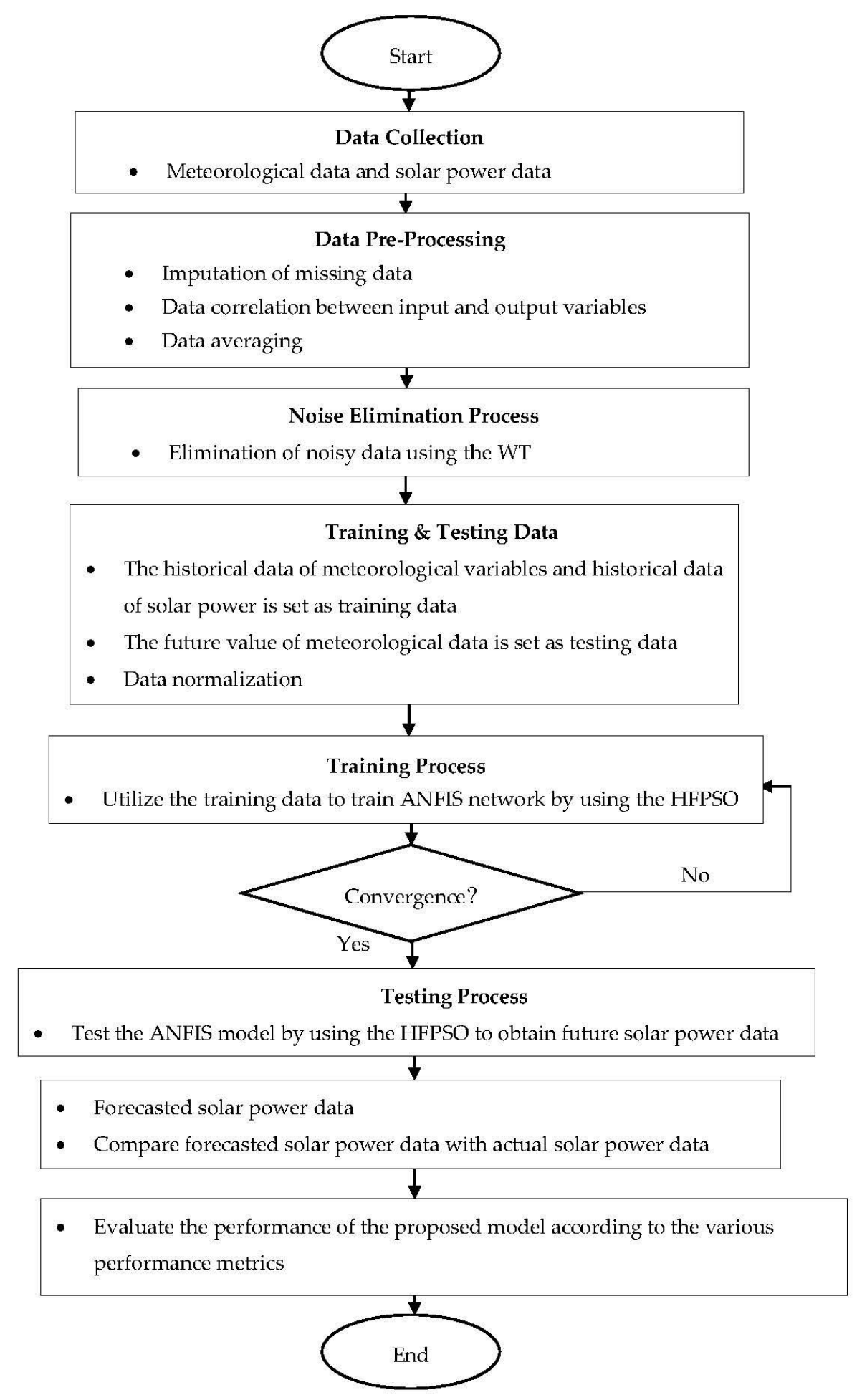

Figure 1. Implementation of forecasting strategy. 


\subsection{Data Collection}

The PV systems utilized by this work is at a latitude of $2.3^{\circ} \mathrm{N}$, a longitude of $102.3^{\circ} \mathrm{E}$ and an altitude of $70 \mathrm{~m}$ above the sea level. Figure 2 displays the installation setup of PV modules as each module is tilted at an angle of $10^{\circ}$. Furthermore, the specifications of the PV system is shown in Table 1.

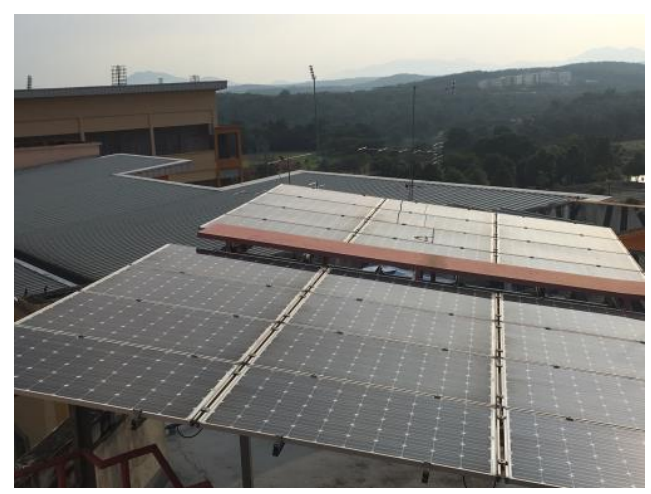

Figure 2. Installation setup of photovoltaic (PV) modules.

Table 1. Specifications of the PV system.

\begin{tabular}{cc}
\hline PV Array & Specification \\
\hline Maximum Power & $130 \mathrm{~W}$ \\
Open Circuit Voltage & $60.4 \mathrm{~V}$ \\
Short Circuit Current & $3.41 \mathrm{~A}$ \\
Maximum Power Voltage & $46.1 \mathrm{~V}$ \\
Maximum Power Current & $2.82 \mathrm{~A}$ \\
Module Efficiency & $9.30 \%$ \\
Array Module Number & 48 Modules \\
\hline
\end{tabular}

The database of this study includes solar power data, which is attained from the PV systems installed on the rooftop of laboratory and administration building at the Faculty of Electrical Engineering in UTeM, Malacca. The solar power data is collected from a solar monitoring system that provides 241,200 measured power values at a one-minute time step resolution with a sampling frequency of 4020 Hertz.

Apart from solar power data, this work obtains meteorological data from a weather station. The collection of the meteorological data is composed of six column matrices. Each column represents the historical values of each meteorological variable that is collected for every minute. The meteorological variables that filled those six columns are known as global radiation, tilted radiation, temperature surrounding, humidity surrounding, panel temperature and wind speed. For all type of variables, day-time data is collected from 8 A.M. until 7.00 P.M.

\subsection{Data Pre-Processing}

The data that has been collected is then pre-processed to ensure a complete and simplified version of data. This pre-processing technique is classified into three steps, namely, missing data imputation, correlation of the input variables with the output variable and data averaging.

\subsubsection{Imputation of Missing Data}

The missing data is the data of a particular variable that cannot be stored in an observation. The frequent occurrence of this missing data is due to sensor malfunction [26]. This study imputes the missing data through a predictive model which is identified as linear interpolation. A linear 
interpolation method fits between a discrete set of known data points in a linear line to create a new data point.

\subsubsection{Correlation between Meteorological Parameters and Solar Power}

This work selects the most relevant input variables according to Pearson correlation in the Excel data analysis tool. From this correlation, the relationship between the two variables is displayed according to the degree of strength that varies from the strongest to the weakest correlation. An analysis of finding a relationship between solar power and meteorological variables is conducted, and the result is shown in Table 2.

Table 2. Correlation value between solar power and meteorological variables.

\begin{tabular}{cc}
\hline Meteorological Variables & Correlation Value \\
\hline Global Radiation & 0.84 \\
Tilted Radiation & 0.86 \\
Temperature Surrounding & 0.48 \\
Humidity Surrounding & -0.49 \\
Panel Temperature & 0.60 \\
Wind Speed & 0.41 \\
\hline
\end{tabular}

According to Table 2, global radiation, tilted radiation and panel temperature depict strong relationships with solar power. Thus, they are used as input variables of the ANFIS model while other variables which contribute a small correlation with solar power are eliminated.

\subsubsection{Data Averaging}

The forecast horizon used by this work is one hour ahead of solar power forecasting. Therefore, the 1-min resolution of collected data is averaged into hourly (60-min) data to match the forecast horizon, providing 4020 data samples. The averaging equation is shown in Equation (1):

$$
\mathrm{x}_{60-\min }=\frac{\sum_{\mathrm{t}=1}^{60} \mathrm{x}_{\mathrm{t}-\mathrm{min}}}{60}
$$

where $x_{60-m i n}$ represents an hourly (60-min) interval value, $\sum_{t=1}^{60} x_{t-m i n}$ denotes the summation of the 1-min interval until the hourly (60-min) interval while $t$ signifies to the time from the first minute until the 60th-minute interval.

\subsection{Elimination of Noisy Data using Wavelet Transform (WT)}

The WT is a method that transforms time series data into time-frequency representation and becomes a superior alternative of the Fourier transform (FT) to analyze stationary and non-stationary data $[24,27]$. In the theory of WT, an original signal is decomposed into two parts; a low-frequency signal and a high-frequency signal. The process is called the wavelet decomposition process, which is represented in Figure 3.

The arrangement in Figure 3 shows the decomposition process of an original signal through the use of a high pass filter and low pass filter to produce a high-frequency signal and a low-frequency signal. The high-frequency signal is known as the detailed signal while the low-frequency signal is identified as the approximation signal. After the first level of the decomposition process, the approximation signal can be further decomposed at several levels. Meanwhile, the detailed signal that exists in the form of noise is filtered through this wavelet decomposition process. 


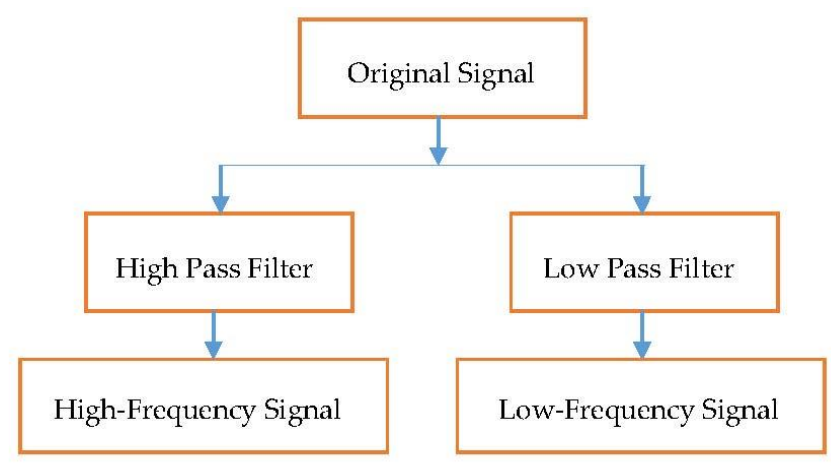

Figure 3. Wavelet decomposition scheme.

In this work, the WT technique is applied to remove noise in meteorological data and solar power data. Hence, the application of this noise removal technique is established according to three important processes, namely, decomposition of the noisy input signal, threshold estimation of wavelet coefficient and reconstruction of the denoised signal.

For the decomposition process, five levels of decomposition trees are chosen because it gives the most reliable result during the wavelet decomposition. Thus, four variables-tilted radiation, global radiation, panel temperature and solar power data-are decomposed five times in this process.

In wavelet analysis, the approximation signal contains vital information of the signal and is rarely affected by noise, while the detailed signal represents noise in the signal [28]. After the decomposition process, the detailed signal needs to pass through the thresholding process. It is implemented by selecting a threshold value for detailed signal in every level of decomposition. At this threshold stage, the coefficients of the detailed signal that are below the threshold value are set to zero, while the coefficients of the detailed signal that lie above the threshold value are subjected to the scaling process and shrinking process. Note that the threshold value of a detailed signal can be estimated by using various threshold estimation methods. This work chooses the threshold estimation method according to the heuristic approach. The outcome of this heuristic approach has shown excellent performance for the fixed type method, because it depicts the most reliable signals compared to other threshold estimation methods.

Once the new coefficients of the detailed signal are obtained, they are reconstructed in the reconstruction process to produce a denoised signal. Those above-mentioned processes are illustrated in Figure 4, where s represents the original signal, $d_{i}$ denotes the detailed signal, $a_{i}$ signifies the approximation signal and symbol $i$ is for the level of decomposition. The original signal in this work can be either the tilted radiation signal, global radiation signal, panel temperature signal or solar power signal. Each of them will pass through the decomposition process, thresholding process and reconstruction process in order to produce a new denoised signal.

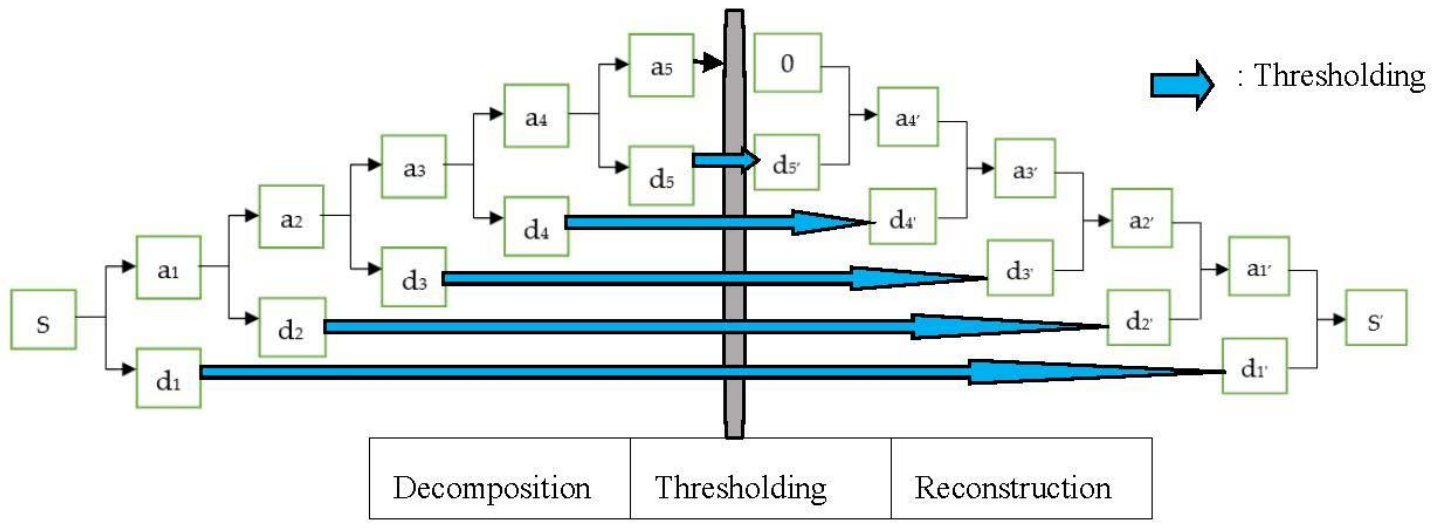

Figure 4. Noise reduction scheme of the wavelet transform (WT). 


\subsection{Adaptive Neuro-Fuzzy Inference System (ANFIS)}

The ANFIS model is a combination of a fuzzy inference system (FIS) and an ANN, which captures the benefits of both models in a single model. The ANN possesses the ability to learn knowledge but deals with deficiency to obtain the output from the decision-making method. Moreover, the FIS method is capable of producing the output from the fuzzy logic decision but does not have any self-operating learning ability [29]. Hence, the benefits of both methods are combined in a single model in order to give a small memorization error which will enhance the performance of the ANFIS model [30].

The design of the ANFIS model consists of two parts, constructing and training. At the construction part, the number and type of membership function are defined. Besides, this construction part includes the division of the input or output data into a number of fuzzy rules which can be achieved by using various methods, such as the grid partitioning method, subtractive clustering method and fuzzy C-means (FCM) clustering method [31]. A large number of fuzzy rules will lead to a complex structure of the ANFIS model. Hence, this paper applies the FCM clustering method to divide the input data in order to obtain a small number of fuzzy rules.

FCM is a data clustering method that assigns each data point to a cluster with a degree that has been specified by a membership grade. In this work, each data point of the panel temperature variable, tiled radiation variable and global radiation variation has been divided into two clusters which are illustrated in Figure 5. $x_{1}$ denotes the panel temperature variable, $x_{2}$ signifies the tilted radiation variable and $x_{3}$ shows the data in global radiation variable.

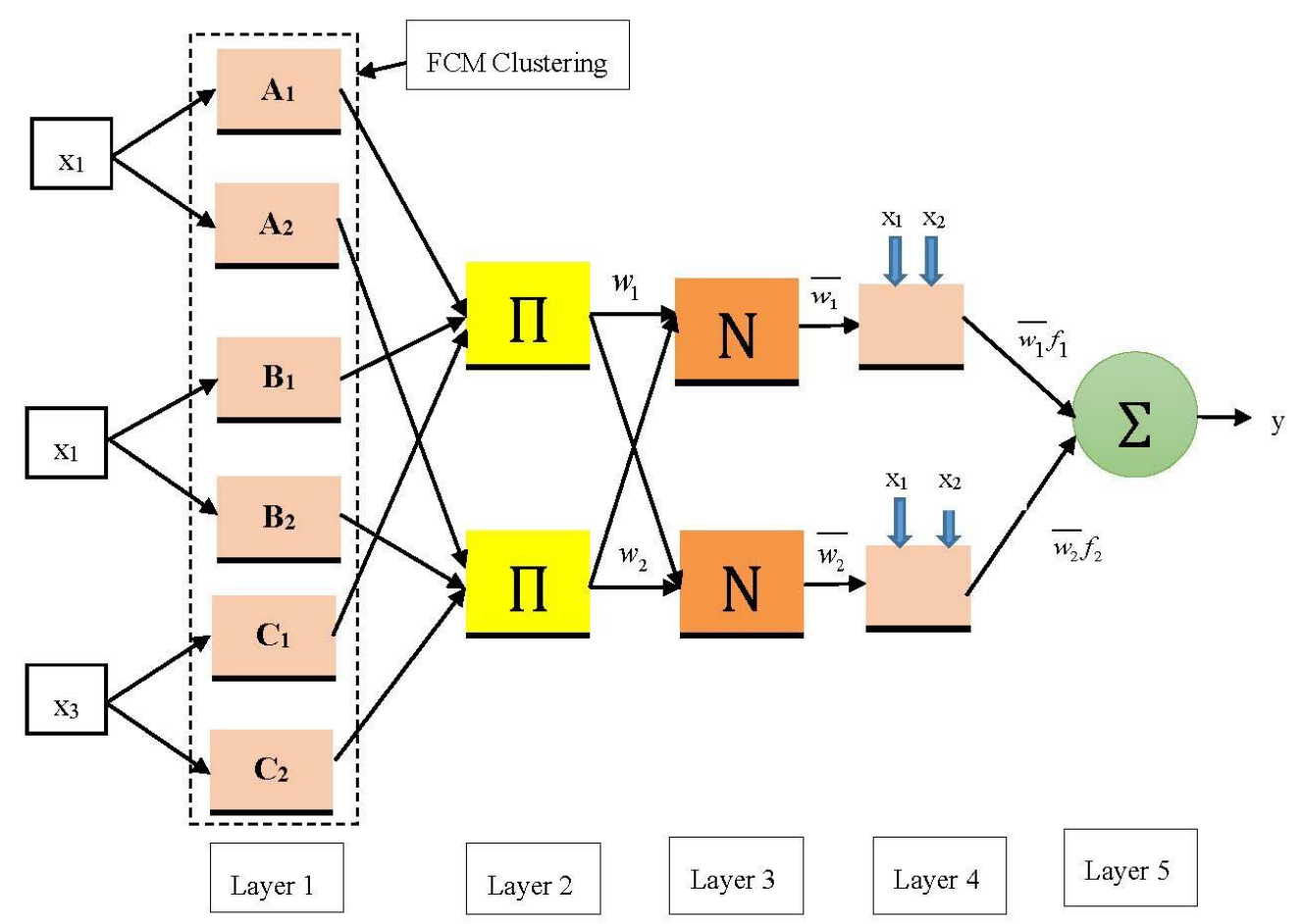

Figure 5. Configuration of the adaptive neuro-fuzzy inference system (ANFIS) [32].

In the training process, the training data pairs are generated to train the ANFIS model. The data pairs comprise of input variables and the corresponding output of the ANFIS model. To the best of the author's knowledge, there is no standard rule to decide the optimum size of datasets for the training and testing processes. Thus, it is decided that the data in this study is divided into $80 \%$ of training data and $20 \%$ of testing data. This means that 4020 samples of observations obtained are divided into 3216 of training samples and 804 of testing samples. The training samples in the ANFIS model will pass through several processes which are explained as follows: 
Layer 1: After the partitioning of training data points into the clusters, each node in Layer 1 is assigned with membership grades of the selected membership function. The assignation of membership function to a node in the first layer is known as the fuzzification process. For FCM clustering, each node in Layer 1 is assigned with the Gaussian membership function which can be shown in Equation (2):

$$
\mathrm{O}_{1, \mathrm{j}}=\mu_{\mathrm{A}_{\mathrm{i}}}(\mathrm{x})=\exp \left(-\frac{1}{2}\left(\frac{\mathrm{x}_{1}-\mathrm{c}_{\mathrm{i}}}{\sigma_{\mathrm{i}}}\right)^{2}\right)
$$

where $O_{k, j}$ represents the output of a $j^{\text {th }}$ node at the $k^{\text {th }}$ layer while $\mu_{A i}$ denotes the membership function of $i^{\text {th }}$ rule $A_{i}$. The grades of this membership function consist of standard deviation $\left(\sigma_{i}\right)$ and mean $\left(c_{i}\right)$ of $i^{\text {th }}$ rule $A_{i}$ where they are known as premise parameters.

Layer 2: The output of the $j^{\text {th }}$ node at the second layer is identified as the firing strength $\left(\mathrm{w}_{\mathrm{j}}\right)$ and it is shown in Equation (3). This layer produces an output by multiplying the membership function of $\mathrm{i}^{\text {th }}$ rules.

$$
\mathrm{O}_{2, \mathrm{j}}=\mathrm{w}_{\mathrm{j}}=\mu_{\mathrm{A}_{\mathrm{i}}}\left(\mathrm{x}_{1}\right) * \mu_{\mathrm{B}_{\mathrm{i}}}\left(\mathrm{x}_{2}\right) * \mu_{\mathrm{C}_{\mathrm{i}}}\left(\mathrm{x}_{3}\right)
$$

Layer 3: The output of $j^{\text {th }}$ node at the third layer is called as normalization of the firing strength $\left(\overline{w_{j}}\right)$ where the firing strength of the respective $\mathrm{i}^{\mathrm{h}}$ rule is divided with the summation of all rules' firing strength as shown in Equation (4).

$$
\mathrm{O}_{3, \mathrm{j}}=\overline{\mathrm{w}_{\mathrm{j}}}=\frac{\mathrm{w}_{1}}{\mathrm{w}_{1}+\mathrm{w}_{2}}
$$

Layer 4: In the fourth layer, the $\mathrm{j}^{\mathrm{th}}$ node calculates the contribution of the $\mathrm{i}^{\text {th }}$ rule to the overall output. This expression is shown in Equation (5) where $p_{i}, q_{i}$ and $r_{i}$ denote the consequent parameters.

$$
\mathrm{O}_{4, j}=\overline{w_{j}} * f_{i}=\frac{w_{1}}{w_{1}+w_{2}}\left(p_{i} x+q_{i} x+r_{i} x\right)
$$

Layer 5: The last process is the defuzzification process where each node produces a single output from the total contribution of each rule as shown in Equation (6).

$$
\mathrm{O}_{5, \mathrm{j}}=\sum\left(\overline{\mathrm{w}_{\mathrm{j}}} * \mathrm{f}_{\mathrm{i}}\right)
$$

In the training process of the ANFIS model, two important parameters, the premise parameters and consequent parameters, must be determined optimally to increase the model performance. The ANFIS utilizes gradient descent backpropagation to estimate the premise parameters and the least squares estimation technique is employed to evaluate the values of consequent parameters.

The training process of the ANFIS model is done iteratively until the network is converged. After that, the testing samples comprised of panel temperature data, tilted radiation data and global radiation data are inserted to the ANFIS model to forecast the future values of solar power.

\subsection{Hybrid Firefly and Particle Swarm Optimization (HFPSO)}

The proposed strategy utilizes hybrid FF and PSO algorithms to optimize the premise parameters of the ANFIS model. A detailed explanation of the FF algorithm, PSO algorithm as well as the proposed hybrid algorithm is described in this section.

\subsubsection{Particle Swarm Optimization (PSO) Algorithm}

PSO is one type of metaheuristic optimization method which is inspired by the behavior of fish schooling and bird flocking [33]. It is preferable in the optimization area as it only requires a few parameter adjustments in optimizing a complex structure [34]. During the optimization process in the $n$-dimensional search space, $X_{i}=\left(x_{1}, x_{2}, x_{3}, \ldots ., x_{n}\right)$, the position and the velocity of a particle are 
initialized. Later, the particle will decide its trajectory according to its historical personal best $\left(\mathrm{P}_{\text {best }}\right)$ solution and historical global best $\left(\mathrm{G}_{\text {best }}\right)$ solution. Then, the particle moves to a new position by using the Equation (7) to Equation (9).

The particle updates its velocity $\left(\mathrm{v}_{\mathrm{i}}(\mathrm{t})\right)$ as in Equation (7) where $\mathrm{C}_{1}$ and $\mathrm{C}_{2}$ are recognized as a cognitive parameter and social parameter, respectively. $r_{1}$ and $r_{2}$ are uniformly distributed numbers in the range of $[0,1]$ while $P_{\text {best }}$ and $G_{\text {best }}$ represent the personal best solution and global best solution, respectively. Besides, $\omega$ is the representation of inertia weight that is updated at each iteration according to Equation (8) where $\omega_{\max }$ and $\omega_{\min }$ are final and initial inertia weight, $\operatorname{Itr}_{\max }$ characterizes the maximum number of iteration and Itr denotes the current iteration number. $\mathrm{v}_{\mathrm{i}}(\mathrm{t}-1)$ refers to the previous velocity of a particle and $x_{i}(t-1)$ represents the previous position of a particle.

$$
\begin{gathered}
\mathrm{v}_{\mathrm{i}}(\mathrm{t})=\omega \mathrm{v}_{\mathrm{i}}(\mathrm{t}-1)+\mathrm{C}_{1} \mathrm{r}_{1}\left(\mathrm{P}_{\text {best }}-\mathrm{x}_{\mathrm{i}}(\mathrm{t}-1)\right)+\mathrm{C}_{2} \mathrm{r}_{2}\left(\mathrm{G}_{\text {best }}-\mathrm{x}_{\mathrm{i}}(\mathrm{t}-1)\right) \\
\omega=\frac{\omega_{\max }-\omega_{\min }}{\mathrm{It} \mathrm{tr}_{\max }} \mathrm{Itr}
\end{gathered}
$$

The current position of each particle $x_{i}(t)$ is updated by using the expression in Equation (9) where $v_{i}(t)$ signifies the current velocity of a particle.

$$
x_{i}(t)=x_{i}(t-1)+v_{i}(t)
$$

\subsubsection{Firefly (FF) Algorithm}

The FF algorithm is one of the recent meta-heuristic optimization algorithms, which was developed by Yang et al. in 2007 [35]. It is inspired by a type of insect (fireflies) which generate rhythmic and short flashes [36]. The light flashes are released as a signal system the fireflies use for communication and hunting [36].

The light intensity (I) of a firefly denotes the brightness of a firefly and it is inversely proportional to a distance of the firefly from the light source (r). This means that the brightness of a firefly is weakened upon increasing the distance of the firefly from the light source. Due to this matter, a firefly can only be seen for a hundred meters, which is an ideal distance for them to communicate. The relation between light intensity and distance of the fireflies from the light source can be obtained in Equation (10), where $I_{S}$ is the intensity of the light source.

$$
\mathrm{I}(\mathrm{r})=\frac{\mathrm{I}_{\mathrm{s}}}{\mathrm{r}}
$$

When the brightness or light intensity of a firefly is increased, the attractiveness of firefly will be increased as well. Every firefly has its own attractiveness that determines how powerful it is to attract other fireflies to its position. Mathematically, the attractiveness $(\beta)$ possessed by each firefly is shown in Equation (11):

$$
\beta(r)=\beta_{0} e^{-\gamma^{r_{i j}^{2}}}
$$

where $\beta_{0}$ represents the attractiveness of a firefly at distance $r=0$ and it can be represented by a constant value. $\gamma$ denotes the coefficient of the light absorption and $\mathrm{r}_{\mathrm{ij}}$ represents the distance between two fireflies, namely, firefly $x_{i}$ and firefly $x_{j}$. The Cartesian distance $\left(r_{i j}\right)$ of two fireflies can be shown in Equation (12):

$$
r_{i j}=\left\|x_{i}-x_{j}\right\|=\sqrt{\sum_{k=1}^{d}\left(x_{i, k}-x_{j, k}\right)^{2}}
$$

where $x_{i, k}$ and $x_{j, k}$ are the $k^{\text {th }}$ component of the position vector for firefly $x_{i}$ and firefly $x_{j}$. Notation $d$ in Equation (12) represents the dimensionality of the search problem. Later, the fireflies will move to a 
position of firefly that has a greater brightness. In this work, firefly $x_{i}$ will move towards the firefly $x_{j}$ according to the movement equation shown in Equation (13).

$$
\mathrm{x}_{\mathrm{i}, \mathrm{k}}(\mathrm{t}+1)=\mathrm{x}_{\mathrm{i}, \mathrm{k}}(\mathrm{t})+\beta_{0} \mathrm{e}^{-\gamma \mathrm{r}_{\mathrm{ij}}{ }^{2}}\left(\mathrm{x}_{\mathrm{j}, \mathrm{k}}(\mathrm{t})-\mathrm{x}_{\mathrm{i}, \mathrm{k}}(\mathrm{t})\right)+\alpha(\text { rand }-0.5)
$$

The first term of Equation (13) refers to the previous position of firefly and the second term depicts the attractiveness equation shown in Equation (11). The third term is governed by the randomization parameter $(\alpha)$ that is responsible to insert randomness in the path followed by the fireflies. Furthermore, the third term of Equation (13) shows the random number (rand) that lies in the range of 0 to 1.

\subsubsection{Proposed Hybridization of HFPSO}

The efficiency of the ANFIS model is largely dependent on the proper choice of the premise or consequent parameters. It is highly important to select the ideal values for both types of parameters to ensure an accurate output representation of the ANFIS model. Previously, premise parameters were estimated according to the gradient descent algorithm. In this work, the premise parameters of the ANFIS model are optimized by a hybrid algorithm that combines the FF and PSO algorithms.

The FF algorithm is advantageous in dealing with non-linear and multi-model optimization problems [37]. Nonetheless, the FF algorithm encounters a problem of getting trapped in the local minima [38]. On the other hand, the PSO algorithm is well known due to its simplicity and ease of the implementation mechanism in the optimization area [39]. However, the PSO has the demerit of premature convergence, which makes it difficult to obtain a better solution [40].

Despite all the advantages offered by the FF and PSO algorithms, they also have some shortcomings that need to be alleviated. Thus, one of the ways to minimize this problem is to hybridize these two algorithms. In this work, the FF and PSO algorithms are combined to prevent the premature convergence of every algorithm, avoid trapping at local optima, and to balance the exploitation process and exploration process [38]. In Figure 6, the flowchart of the proposed HFPSO algorithm which is used by this work is shown.

The detailed explanation of the procedures in the flowchart is explained as follows:

Step 1: Initially, all of the input parameters used in the FF and PSO algorithm are defined.

[Xmin: Minimum search range limit $=0$, Xmax: Maximum search range limit $=1$, Itr $_{\text {max }}$ : Number of maximum iteration $=150, n$ Pop: Number of Population $=15, C_{1}$ : Cognitive parameter $=0.7, C_{2}$ : Social parameter $=1.7, \boldsymbol{w}:$ Inertia weight $=1, \boldsymbol{\alpha}:$ Randomization parameter $=0.6, \boldsymbol{\beta}_{0}:$ Attractiveness of fireflies at zero distance $=2, \gamma$ : Coefficient of the light absorption $=89]$

Step 2: The position of the population is initialized at random.

Step 3: Fitness value, the $P_{\text {best }}$ solution and $G_{\text {best }}$ solution are calculated and assigned to the HFPSO algorithm.

Step 4: The distance between $P_{\text {best }}$ and $G_{b e s t}$ with a population $x_{j}$ are identified as $r_{p x}$ and $r_{g x}$, respectively. At this stage, the values of $r_{p x}$ and $r_{g x}$ are calculated according to Equation (14) and Equation (15). Notation d in both equations represents the dimensionality of the search problem.

$$
\begin{aligned}
& r_{p x}=\sqrt{\sum_{k=1}^{d}\left(P_{\text {besti,k }}-x_{j, k}\right)^{2}} \\
& r_{g x}=\sqrt{\sum_{k=1}^{d}\left(G_{\text {besti, }}-x_{j, k}\right)^{2}}
\end{aligned}
$$

Step 5: At this stage, the fitness of population $x_{i}$ and population $x_{j}$ is compared. 
Step 6: If the fitness of the population $x_{j}$ is greater than population $x_{i}$, the local search will be started and handled by FF algorithm in updating new position according to Equation (13). Otherwise, the population will be handled by the PSO algorithm and it will update the new position according to Equation (16).

$$
x_{i, k}(t+1)=\omega x_{i, k}(t)+C_{1} e^{-r_{p x}{ }^{2}}\left(P_{\text {besti, }}(t)-x_{i, k}(t)\right)+C_{2} e^{-r_{g x}{ }^{2}}\left(G_{\text {besti, }}(t)-x_{i, k}(t)\right)+\alpha(\gamma-0.5)
$$

Step 7: The values for fitness, $P_{\text {best }}$ and $G_{\text {best }}$ are updated.

Step 8: Fireflies are sorted in descending order according to their fitness values.

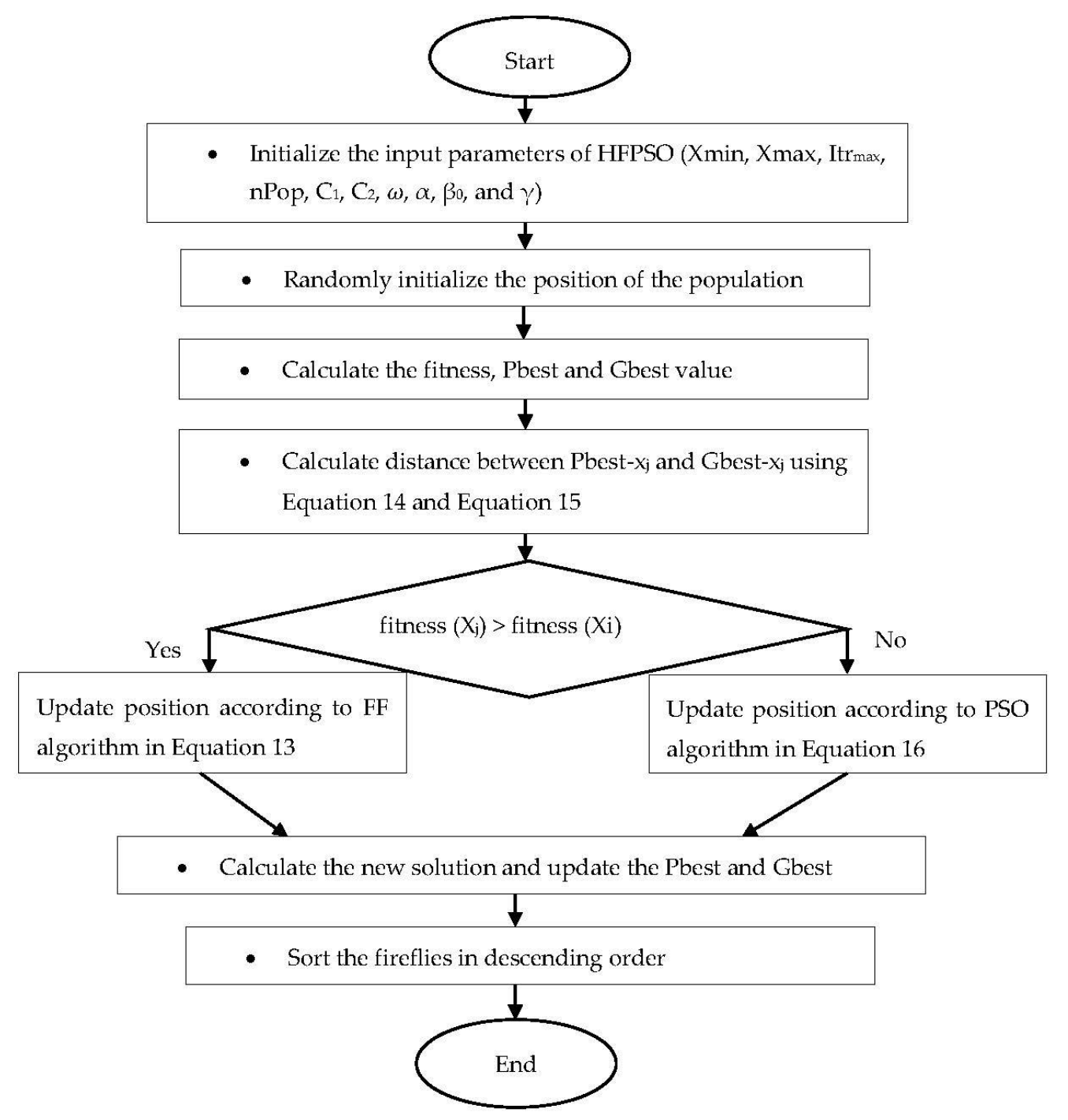

Figure 6. Flowchart of proposed hybrid firefly and particle swarm optimization (HFPSO).

\section{Performance Metrics}

The accuracy of the forecasting technique is evaluated by the performance metrics of the root mean square error (RMSE), normal root mean square error (NRMSE), mean absolute error (MAE), Willmott's 
index of agreement (WIA) [41] and Legate's coefficient of efficiency (LCE) [41]. All performance metrics are shown in Equation (17) to Equation (21):

$$
\begin{gathered}
\text { RMSE }=\sqrt{\frac{1}{n} \sum_{i=1}^{n}\left(I_{f}-I_{m}\right)^{2}} \\
\text { NRMSE }=\frac{\left(\frac{1}{n} \sum_{i=1}^{n}\left(I_{f}-I_{m}\right)^{2}\right)^{1 / 2}}{\frac{1}{n} \sum_{i=1}^{n}\left(I_{m}\right)} \\
\text { MIA }=1-\frac{1}{n} \sum_{i=1}^{n}\left|I_{f}-I_{m}\right| \\
\left(\sum_{i=1}^{n}\left(\mid \sum_{i=1}^{n}\left(I_{f}-\overline{I_{m}}|+| I_{m}-\overline{I_{m}} \mid\right)^{2}\right)\right. \\
\text { LCE }=1-\frac{\left(\sum_{i=1}^{n}\left(I_{f}-I_{m}\right)^{2}\right)}{\left(\sum_{i=1}^{n}\left(I_{m}-\overline{I_{m}}\right)^{2}\right)}
\end{gathered}
$$

where $\mathrm{I}_{\mathrm{f}}$ denotes the forecasted values, $\mathrm{I}_{\mathrm{m}}$ represents the actual values, $\overline{\mathrm{I}_{\mathrm{m}}}$ signifies the mean of actual values, $\overline{\mathrm{I}_{\mathrm{f}}}$ indicates the mean of forecasted values and $n$ is for a number of observations.

Estimation of the RMSE provides the variability measurement of forecasted and actual values [42]. It is one of the standard metrics used to identify the efficiency of the forecasting model [43]. Furthermore, the MAE offers an absolute gap between the forecasted and actual values [44]. The forecasting process is becoming more precise for a smaller value of the RMSE, NRMSE and MAE [43,44]. Besides, the WIA and LCE metrics are the indexes used to specify the relationship between the actual and forecasted values. These metrics give a value between 0 and 1 where the value of 1 implies a robust positive relationship, and the value of 0 denotes zero relationships between actual and forecasted values. An accurate forecasting model provides the WIA or LCE with a value closer to 1 . All above-mentioned performance metrics are the added advantages that indicate the performance of the proposed hybrid model.

\section{Simulation Results}

This paper proposes WT-ANFIS-HFPSO as the short-term forecasting model of a solar power system in Malacca, Malaysia. The proposed model is different from the traditional forecasting model as it is a perfect combination of the following parts: (1) a WT to remove the noises in the panel temperature data, tilted radiation data, global radiation data and solar power data; (2) an ANFIS as the forecasting tool of future solar power data; and (3) HFPSO to optimize the premise parameters of the ANFIS model. The results are analyzed according to three conditions of days, namely, sunny days, partially cloudy days and cloudy days. Sunny days referred to the days with the highest average daily value of solar radiation while cloudy days are days with the lowest average daily value of solar radiation. Three days that have been specified for each condition of the day are depicted in Table 3 . The comparative performance analysis is shown and discussed under these three conditions of days which involves the analysis of the five performance metrics (the MAE, RMSE, NRMSE, WIA, and LCE) for every forecasting strategy. Note that this work displays the results for every day in the time step of $1 \mathrm{~h}$. 
Table 3. Specified days for each condition of the day.

\begin{tabular}{cccc}
\hline Condition of the Day & Sunny & Partially Cloudy & Cloudy \\
\hline \multirow{2}{*}{ Date } & 30th September 2016 & 1st October 2016 & 14th November 2016 \\
& 15th October 2016 & 16th November 2016 & 1st November 2016 \\
& 2nd October 2016 & 10th November 2016 & 17th October 2016 \\
\hline
\end{tabular}

\subsection{Performance Analysis for Sunny Days}

In this subsection, the performance of WT-ANFIS-HFPSO model is compared with four solar power forecasting strategies which are known as the WT-ANFIS-FF, WT-ANFIS-PSO, WT-ANFIS and the ANFIS model. Solar power and meteorological signals are often contaminated by noise that is represented in the form of fluctuations, variations or spikes. On sunny days, the solar power signal is less fluctuating and it is not greatly impacted by noise. Hence, a forecasting model rarely requires any technique to remove noisy data on sunny days. However, this work has applied the WT technique to remove noise in solar power signals and meteorological signals on sunny days. The result of this work is shown in Table 4, where the applicability of the WT to remove the noisy signals on sunny days is deemed to be reasonable. This is proven by referring to the values of the MAE, RMSE, LCE and WIA of WT-ANFIS that are better than the ANFIS model.

Table 4. Performance comparison of forecasting models on sunny days.

\begin{tabular}{ccccc}
\hline Forecasting Model & MAE $(\mathbf{W})$ & RMSE $(\mathbf{W})$ & LCE & WIA \\
\hline WT-ANFIS-HFPSO & 44.8471 & 56.4235 & 0.99427 & 0.99857 \\
WT-ANFIS-FF & 200.3330 & 234.1070 & 0.90366 & 0.96742 \\
WT-ANFIS-PSO & 53.5802 & 64.2567 & 0.99267 & 0.99813 \\
WT-ANFIS & 46.9559 & 58.6801 & 0.99395 & 0.99850 \\
ANFIS & 128.9838 & 153.3567 & 0.97631 & 0.99365 \\
\hline
\end{tabular}

Note: Mean Absolute Error (MAE), Root Mean Square Error (RMSE), Legate's coefficient of efficiency (LCE) and Willmott's index of agreement (WIA).

The efficiency of the WT-ANFIS depends on appropriately choosing the premise parameters or consequent parameters. In this work, the HFPSO has been proposed to determine the optimal values of premise parameters and the result obtained is compared with the application of a single PSO and FF algorithms. As can be seen in Table 4, the performance of the proposed WT-ANFIS-HFPSO model on sunny days gives supreme performance evaluation (MAE, RMSE, LCE and WIA) results compared to the WT-ANFIS-FF and WT-ANFIS-PSO. These results have verified the effectiveness of combining the WT-ANFIS with the HFPSO model.

Figure 7 depicts the actual and forecasted average solar power of WT-ANFIS-HFPSO on sunny days. It is known from Figure 7 that the forecasted solar power data has less variation with the actual solar power data and this result verifies the higher precision and accuracy of the WT-ANFIS-HFPSO to forecast solar power data on sunny days.

\subsection{Performance Analysis for Partially Cloudy Days}

In terms of partially cloudy days, the performance of the WT-ANFIS-HFPSO is compared with several forecasting models and the results are tabulated in Table 5. When the performance of the WT-ANFIS and ANFIS models are compared, the results obtained are similar to the results discussed in Section 4.1. The utilization of the WT with the ANFIS model has improved the performance of the forecasting model. This can be proven specifically when the MAE and RMSE values are lowered from $92.48 \mathrm{~W}$ in the ANFIS to $48.98 \mathrm{~W}$ in the WT-ANFIS and $109.28 \mathrm{~W}$ in the ANFIS to $61.58 \mathrm{~W}$ in the WT-ANFIS, respectively. Apart from that, the LCE value has been improved from 0.9221 in the ANFIS to 0.9334 in the WT-ANFIS. There is also an improvement in the WIA value as it increases from 0.9791 in the ANFIS to 0.9857 in the WT-ANFIS. Smaller values of the MAE and RMSE represent small 
differences that exist between the forecasted and actual solar power data. Meanwhile, a high value of the LCE and WIA signifies that the forecasted values of solar power are closer to the actual ones. Hence, the application of the WT as a denoising tool has helped improve the ANFIS model to forecast solar power on partially cloudy days.

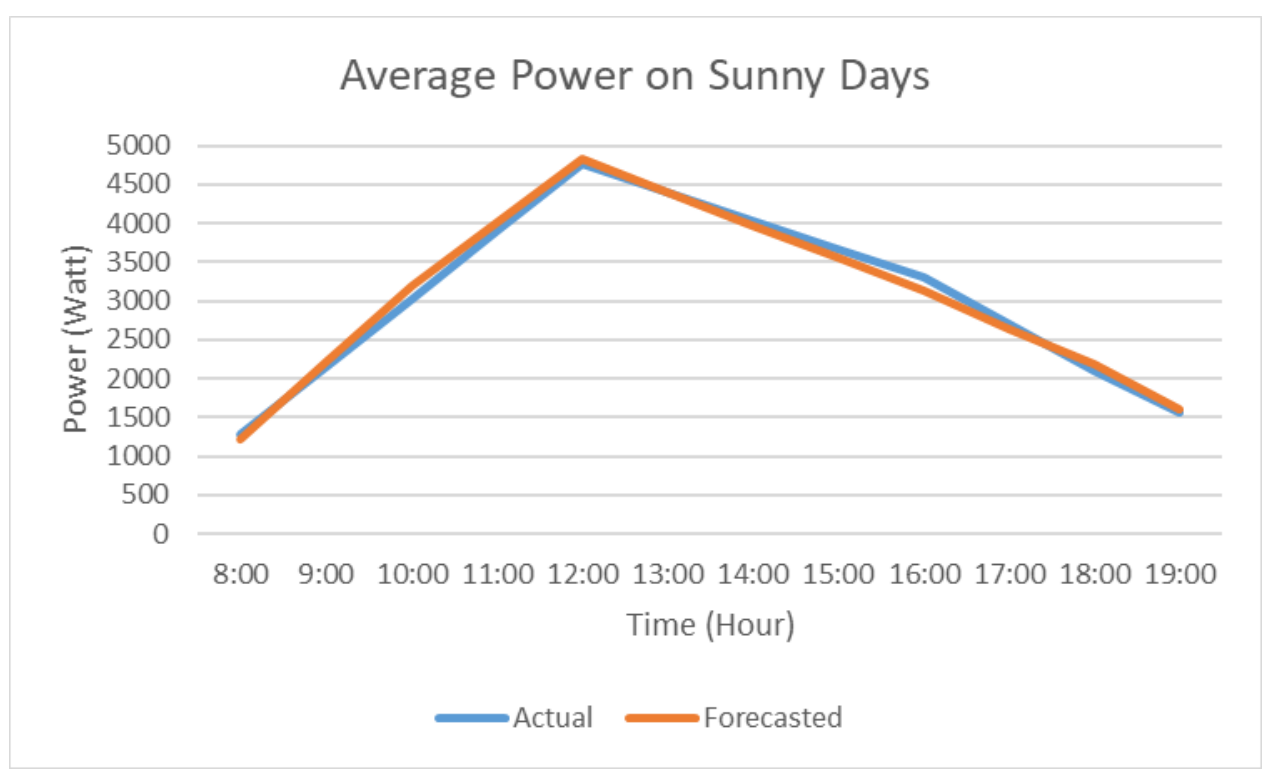

Figure 7. Actual versus forecasted curve of average solar power for the WT-ANFIS-HFPSO on sunny days.

Table 5. Performance comparison of forecasting models on partially cloudy days.

\begin{tabular}{ccccc}
\hline Forecasting Model & MAE $(\mathbf{W})$ & RMSE $(\mathbf{W})$ & LCE & WIA \\
\hline WT-ANFIS-HFPSO & 37.5361 & 50.6254 & 0.94786 & 0.98905 \\
WT-ANFIS-FF & 79.5826 & 91.9239 & 0.88303 & 0.96935 \\
WT-ANFIS-PSO & 38.0304 & 51.4952 & 0.94318 & 0.98824 \\
WT-ANFIS & 48.9825 & 61.5801 & 0.93337 & 0.98569 \\
ANFIS & 92.4802 & 109.2813 & 0.92208 & 0.97913 \\
\hline
\end{tabular}

Furthermore, the combination result of the WT-ANFIS with the HFPSO algorithm is compared with the WT-ANFIS-FF and WT-ANFIS-PSO. Similar to the discussion made in Section 4.1, all of the performance metric values of the WT-ANFIS-HFPSO are superior to the WT-ANFIS-FF and WT-ANFIS-PSO. These results specify that the hybridization of the FF and PSO has the capability to improve the performance of the WT-ANFIS better than utilization of an individual FF and an individual PSO. In sum, the advantage of the WT to remove noisy data and the benefit of HFPSO to obtain the optimal values of premise parameters have increased the accuracy of the WT-ANFIS-HFPSO model to forecast solar power data.

Figure 8 shows the behavior of forecasted solar power data for the WT-ANFIS-HFPSO on partially cloudy days. It can be found that the forecasted solar power data manages to capture the trend of the actual solar power data. Hence, it is obvious that the WT-ANFIS-HFPSO not only capable of forecasting solar power data on sunny days, but it manages to forecast solar power data on partially cloudy days with high precision and accuracy. 


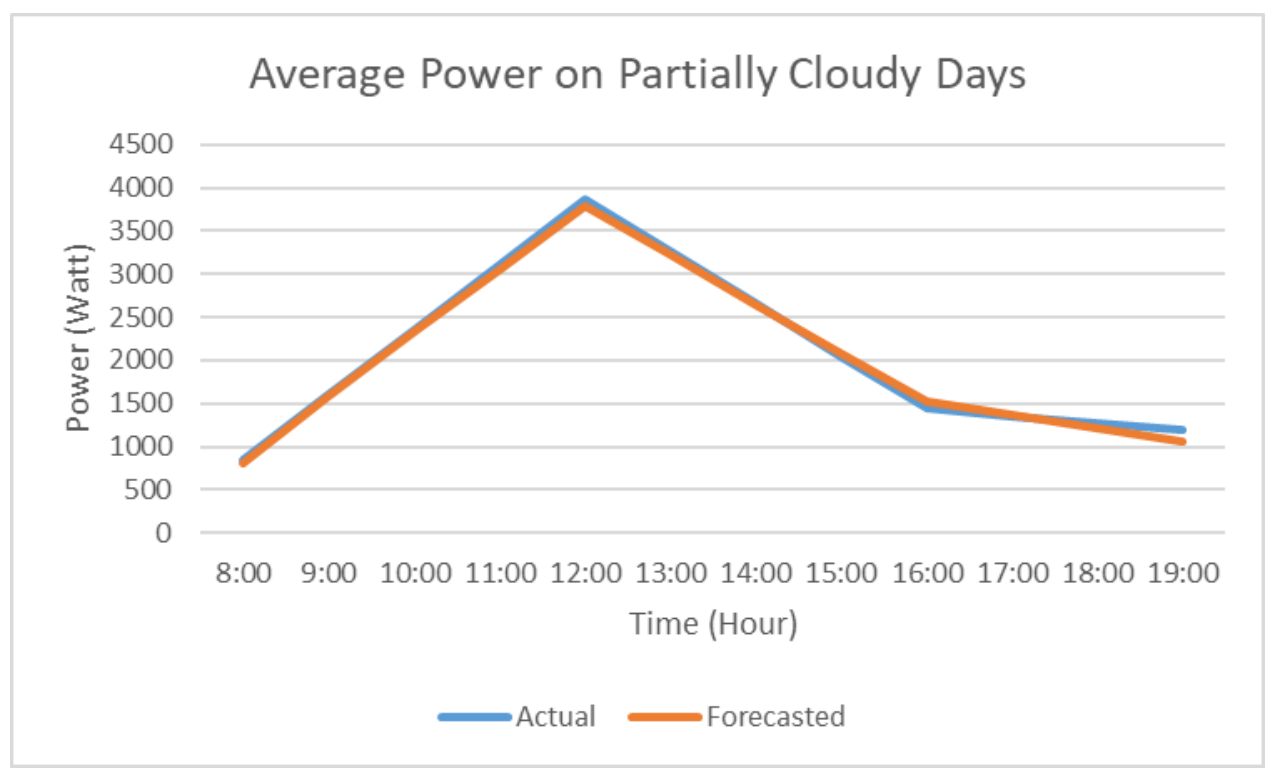

Figure 8. Actual versus forecasted curve of average solar power for WT-ANFIS-HFPSO on partially cloudy days.

\subsection{Performance Analysis for Cloudy Days}

On cloudy days, solar power data has greater fluctuation and volatility. Thus, the usage of the WT will remove the noisy data as well as increase the forecasting accuracy of the ANFIS model. This idea is in accordance with the comparison results shown by WT-ANFIS and ANFIS models in Table 6. It is obvious that the values of the MAE, RMSE, LCE and WIA obtained from the WT-ANFIS are better than the ANFIS model and these results have signified the goodness of the WT to be integrated with the ANFIS model during solar power forecasting.

Table 6. Performance comparison of forecasting models on cloudy days.

\begin{tabular}{ccccc}
\hline Forecasting Model & MAE $(\mathbf{W})$ & RMSE $(\mathbf{W})$ & LCE & WIA \\
\hline WT-ANFIS-HFPSO & 25.6249 & 32.0590 & 0.98089 & 0.99531 \\
WT-ANFIS-FF & 34.6194 & 43.3176 & 0.96490 & 0.99121 \\
WT-ANFIS-PSO & 26.0965 & 32.5488 & 0.98021 & 0.99511 \\
WT-ANFIS & 32.6104 & 41.0914 & 0.96757 & 0.99091 \\
ANFIS & 38.9978 & 51.7635 & 0.95663 & 0.98795 \\
\hline
\end{tabular}

Additionally, great performance is achieved via the utilization of HFPSO to optimize the premise parameters of the WT-ANFIS. By following the results shown in Table 6, the MAE of $25.62 \mathrm{~W}$ and the RMSE of $32.06 \mathrm{~W}$ shown by the WT-ANFIS-HFPSO are smaller than the MAE and RMSE values obtained from the WT-ANFIS-FF and WT-ANFIS-PSO. Apart from that, the WT-ANFIS-HFPSO produces the highest enhancement of the LCE and WIA values. These results have further indicated the suitability of the proposed WT-ANFIS-HFPSO for solar power forecasting on cloudy days.

The average power curve of the WT-ANFIS-HFPSO is shown in Figure 9. As can be seen in Figure 9, there is a slight variation between the forecasted and actual solar power data. The variations are mainly attributed to the higher fluctuations of solar power on cloudy days that make the forecasting process to become unstable. However, the result of the WT-ANFIS-HFPSO on cloudy days is considered satisfying as the forecasted solar power data manages to capture the trends of the actual solar power data. 


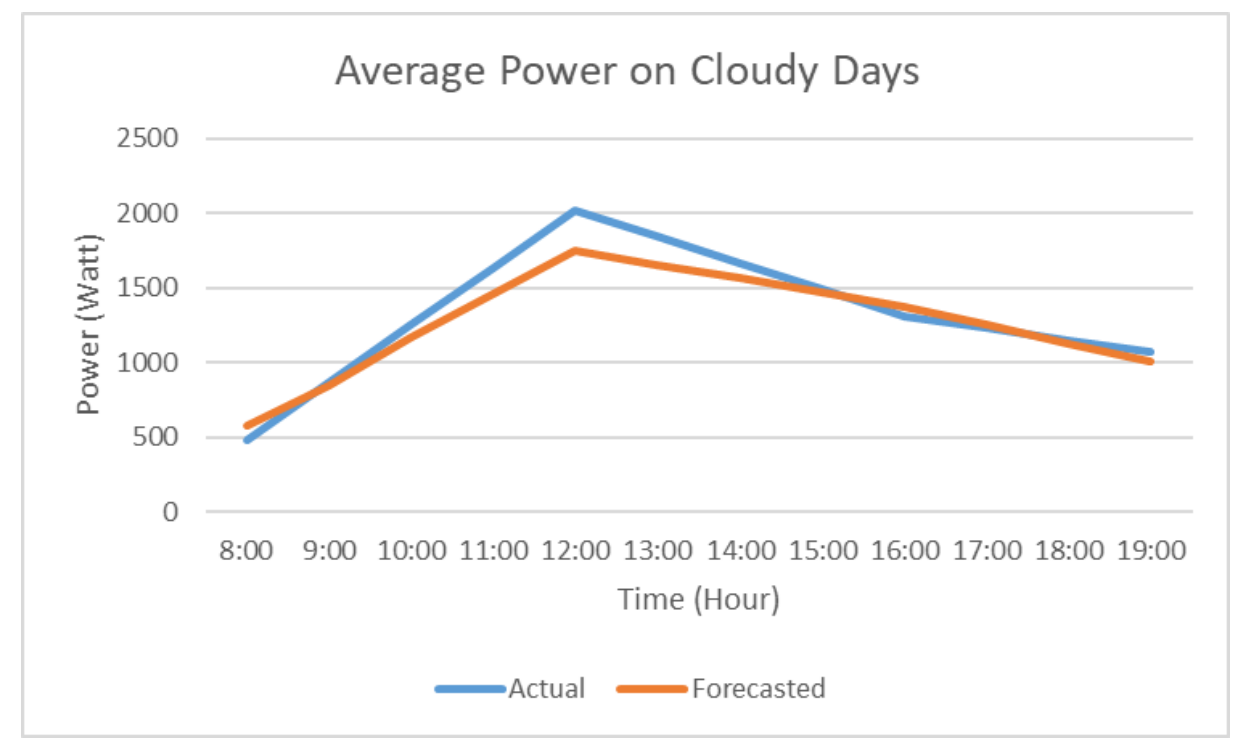

Figure 9. Actual versus forecasted curve of average solar power for WT-ANFIS-HFPSO on cloudy days.

\subsection{Performance Comparison of Proposed Work with other Forecasting Strategies}

In analyzing the connection between the condition of the day with the model accuracy, the MAE, RMSE and NRMSE values obtained from several forecasting models are plotted in the histogram bars as shown in Figures 10-12.

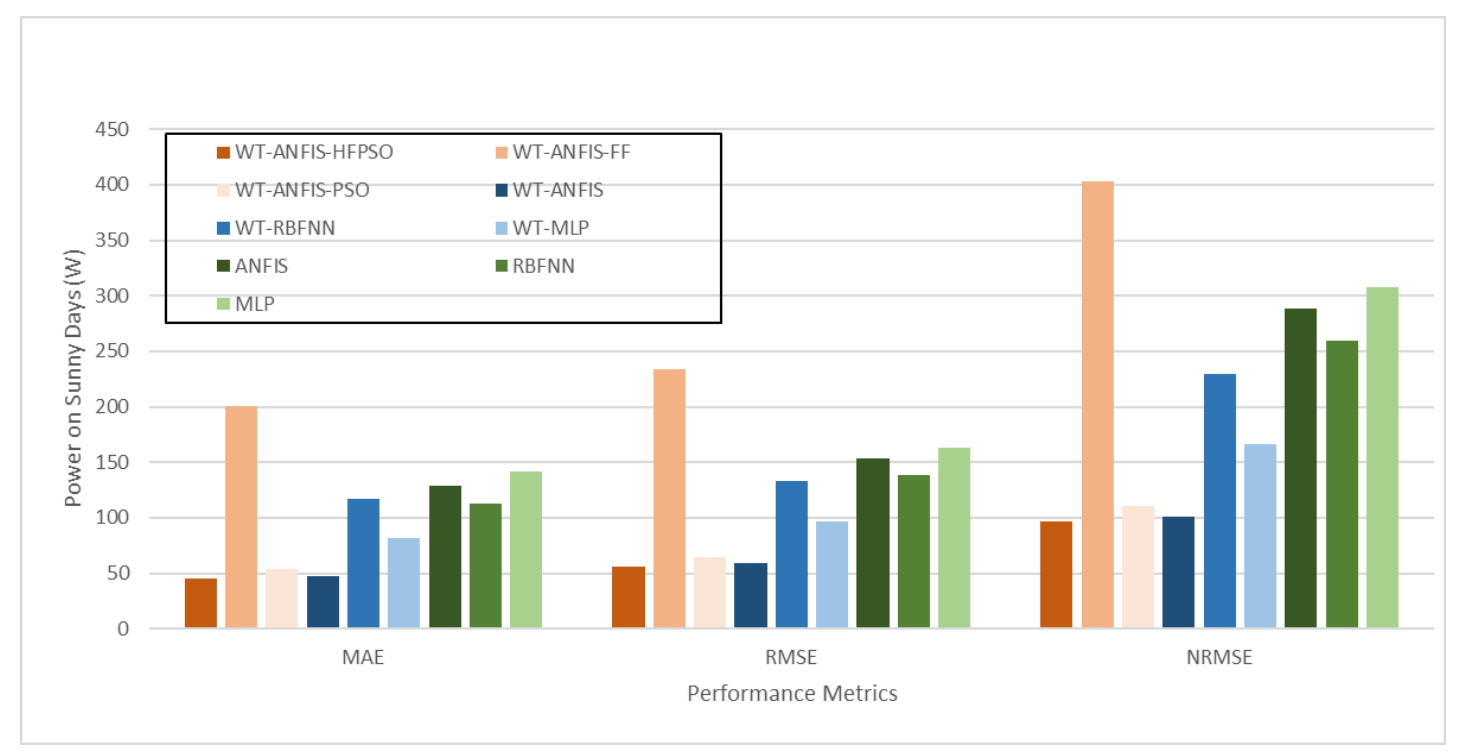

Figure 10. Comparison of forecasting models in terms of the MAE, RMSE and RMSE on sunny days.

Figure 10 illustrates the changing bars of several forecasting models on sunny days according to the specific performance metrics (MAE, RMSE and NRMSE). On sunny days, the solar power data is not greatly impacted by the noise as it experiences less fluctuation. However, this work applies the WT to remove the noisy data on sunny days. The result of this work shows the significant implementation of the WT to eliminate noisy signals due to the performance improvement offered. This is revealed in Figure 10, where the heights of all blue bars (WT-ANFIS, WT-RBFNN and WT-MLP) for the MAE, RMSE and NRMSE are lower than all green bars (ANFIS, RBFNN and MLP). It is concluded that the application of a denoising tool will increase the performance of the forecasting models. 


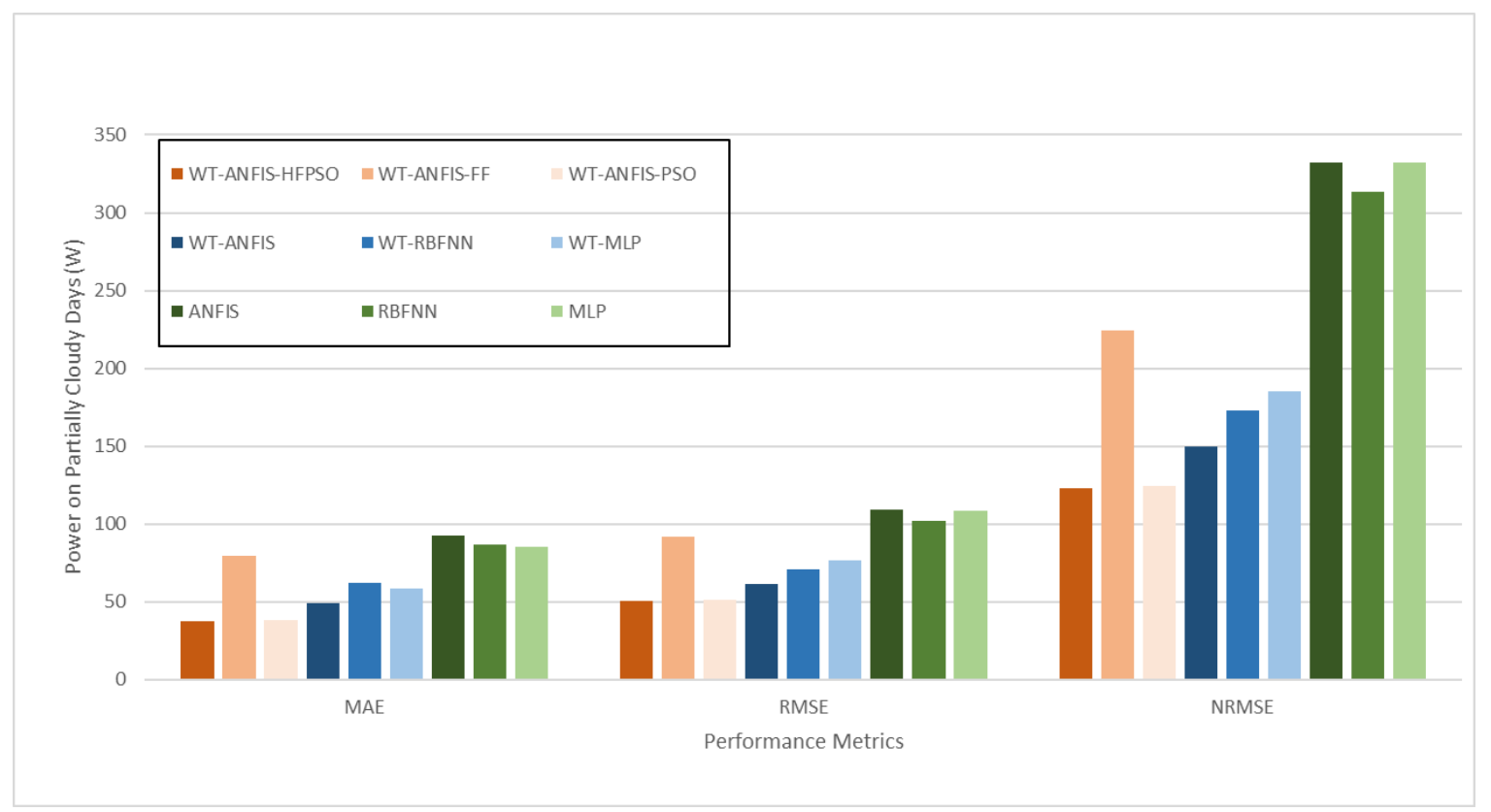

Figure 11. Comparison of forecasting models in terms of the MAE, RMSE and RMSE on partially cloudy days.

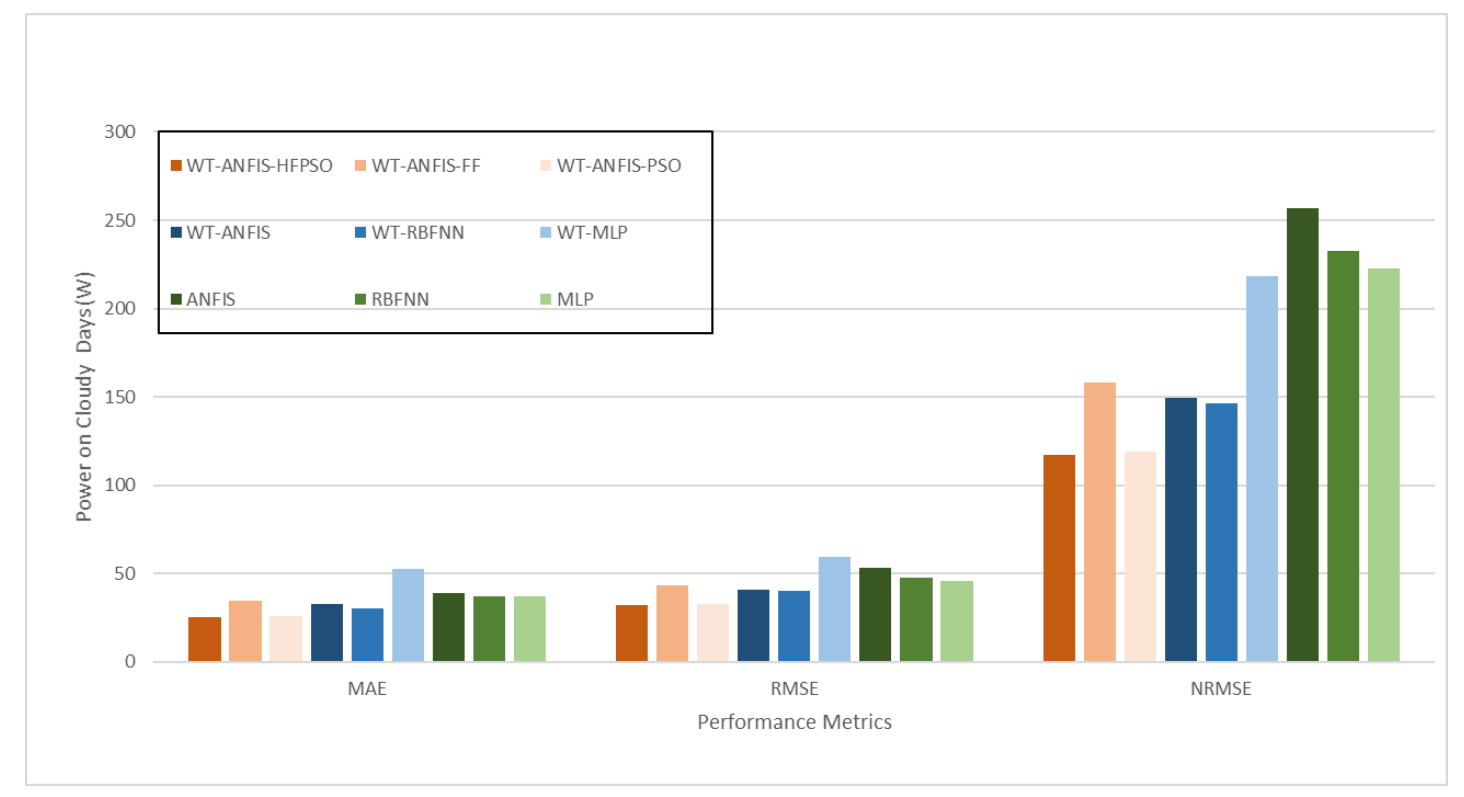

Figure 12. Comparison of forecasting models in terms of the MAE, RMSE and RMSE on cloudy days.

The performance of a forecasting model can be further improved by using an optimization algorithm. This work integrates the WT-ANFIS model with two optimization algorithms known as the FF and PSO algorithms. By referring to the values of the MAE, RMSE and NRMSE in Figure 10, the utilization of the WT-ANFIS with an individual PSO and FF has not increased the accuracy of the WT-ANFIS. This is may due to the premature convergence of the PSO algorithm, as well as the condition of the FF algorithm that is trapped at local minima. Hence, it is obvious that the employment of an optimization algorithm to a forecasting model on sunny days has not improved the model's accuracy. To mitigate this matter, the FF and PSO algorithms were hybridized and the result of this hybridization has improved the performance of WT-ANFIS. This can be proven from Figure 10, where the dark orange bar (WT-ANFIS-HFPSO) has provided the lowest MAE, RMSE and NRMSE values than other forecasting strategies. 
The changing bars in Figures 11 and 12 signify the MAE, RMSE and NRMSE values of various forecasting models on partially cloudy days and cloudy days. The solar power data on partially cloudy days and cloudy days presents higher volatility and fluctuation. These phenomena lead to the existence of noise in data. To overcome the noise problem, the WT is applied to the data before it is introduced to the forecasting models. According to Figures 11 and 12, the implementation of the WT has improved the performance of the forecasting model. This can be proven according to the MAE, RMSE and NRMSE values, where the heights of all blue bars which represent the WT-ANFIS, WT-RBFNN and WT-MLP models are lower than all green bars that signify the ANFIS, RBFNN and MLP models. In sum, an improved forecasting model on cloudy days and partially cloudy days can be obtained from the utilization of a WT to remove noisy data.

Furthermore, the PSO and FF algorithms are applied to the WT-ANFIS to improve the performance of the forecasting model. In Figures 11 and 12, the employment of a PSO has increased the performance of the WT-ANFIS. This is revealed by the fact that the light orange bar (WT-ANFIS-PSO) for the RMSE, MAE and RMSE in both figures is lower than the dark blue bar (WT-ANFIS). On the other hand, the integration of the FF algorithm has not improved the performance of the WT-ANFIS for cloudy days and partially cloudy days. This is may due to the condition of the FF algorithm that is trapped in the local minima. Thus, this work implements the hybridization of the FF and PSO algorithms to overcome the disadvantages offered by each optimization algorithm. The result of this hybridization has improved the performance of the WT-ANFIS on cloudy days and partially cloudy days. This is proved by Figures 11 and 12, where the dark orange bar (WT-ANFIS-HFPSO) has provided the lowest MAE, RMSE and NRMSE values compared to the other forecasting strategies.

In summary, it is obvious that the application of the WT has improved the accuracy of the forecasting model for every condition of the day. However, the applicability degree of a single optimization algorithm (FF and PSO) to a forecasting model in every condition of the day is not fixed. For sunny days, the employment of the FF and PSO did not increase the performance of the WT-ANFIS. For partially cloudy days and cloudy days, the PSO algorithm improved the performance of the WT-ANFIS. However, the FF algorithm has not shown the same trend of results with the PSO, as it tends to deteriorate the precision of the WT-ANFIS model on both conditions of the day. Hence, both algorithms have been hybridized. Specifically speaking, the height differences of bars for sunny days, partially cloudy days and cloudy days have revealed the superiority of the proposed model, the WT-ANFIS-HFPSO, to forecast hourly solar power data.

\section{Conclusions}

In this study, a model which is known as the WT-ANFIS-HFPSO, was developed which aims to achieve supreme model performance for solar power forecasting. The proposed model has utilized the WT to remove noisy data and has hybridized FF and PSO algorithms to optimize the premise parameters of the ANFIS model. The results of the proposed work are divided into three conditions of days, which are sunny days, partially cloudy days and cloudy days. It appears from the results that the usage of the WT has improved the forecasting model, particularly the ANFIS model, for all conditions of the days. These can be proven according to the small values of the MAE and RMSE, as well as the high values of the LCE and WIA that are shown by the WT-ANFIS. This work applies a hybrid algorithm which combines the FF and PSO algorithms. The outcome has shown the supreme performance of the WT-ANFIS-HFPSO when it is compared with the WT-ANFIS-FF and WT-ANFIS-PSO. This work also compares the performance of the WT-ANFIS-HFPSO for every condition of the day with other forecasting strategies such as the WT-ANFIS-PSO, WT-ANFIS-FF, WT-ANFIS, WT-RBFNN, WT-MLP, ANFIS, RBFNN and MLP. Compared with the selected forecasting strategies, the WT-ANFIS-HFPSO yields better results. The proposed model provides the lowest RMSE, MSE and NRMSE values that outperform other eight forecasting strategies. These demonstrated results have affirmed the effectiveness of the WT-ANFIS-HFPSO in providing the best predictive capability of solar power. However, the usage of all above-mentioned forecasting models is limited to a dataset from the UTeM, 
Malacca. This means that all of the forecasting models cannot be generalized to different locations. Hence, the future direction of this work should include datasets from various locations to estimate the efficiency of the proposed model, the WT-ANFIS-HFPSO, to forecast hourly solar power data.

Author Contributions: Conceptualization, N.A.A.; Formal analysis, N.N.A.; Methodology, N.A.A.; Resources, C.K.G.; Supervision, N.A.R.; Validation, N.A.R.; Writing-original draft, N.A.A.; Writing-review \& editing, N.A.R.

Funding: This research and the APC were funded by the Higher Institution Centre of Excellence (HICoE) Program Research Grant and Centre for Research Grant Management (PPGP) at the University of Malaya, grant number [UMPEDAC-2018 (MOHE HICoE-UMPEDAC) and RU005-2015].

Acknowledgments: The authors would like to acknowledge the financial support of the Centre for Research Grant Management (PPGP) at the University of Malaya [RU005-2015, MATCHING GRANT (UMPEDAC AND HLAF]; Higher Institution Centre of Excellence (HICoE); and Ministry of Education Malaysia (MOE HICoE-UMPEDAC).

Conflicts of Interest: The authors declare no conflict of interest.

\section{Nomenclature}

\begin{tabular}{|c|c|}
\hline ANFIS & Adaptive Neuro-Fuzzy Inference System \\
\hline ANN & Artificial Neural Network \\
\hline AR & Auto-Regressive \\
\hline ARMAX & Auto-Regressive Moving Average with Exogenous Input \\
\hline $\mathrm{CO}_{2}$ & Carbon Dioxide \\
\hline FF & Firefly \\
\hline FIS & Fuzzy Inference System \\
\hline FT & Fourier Transform \\
\hline GSR & Global Solar Radiation \\
\hline HFPSO & Hybrid Firefly and Particle Swarm Optimization \\
\hline $\mathrm{HICoE}$ & Higher Institution Centre of Excellence \\
\hline LCE & Legate's Coefficient of Efficiency \\
\hline LS-SVM & Least Square-Support Vector Machine \\
\hline MAE & Mean Absolute Error \\
\hline MAPE & Mean Absolute Percentage Error \\
\hline MLP & Multi-Layer Perceptron \\
\hline MLR & Multiple Layer Regression \\
\hline MOE & Ministry of Education in Malaysia \\
\hline NRMSE & Normal Root Mean Square Error \\
\hline PPGP & Centre for Research Grant Management \\
\hline PSO & Particle Swarm Optimization \\
\hline PV & Photovoltaic \\
\hline RBFNN & Radial Basis Function Neural Network \\
\hline RMSE & Root Mean Square Error \\
\hline SVM & Support Vector Machine \\
\hline SVR & Support Vector Regression \\
\hline UMPEDAC & University of Malaya Power Energy Dedicated Advanced Centre \\
\hline UTeM & Universiti Teknikal Malaysia Melaka \\
\hline WIA & Willmott's Index of Agreement \\
\hline WT & Wavelet Transform \\
\hline$x_{60-\min }$ & Hourly interval value \\
\hline$\mu_{\mathrm{A}_{\mathrm{i}}}$ & Membership function of $i^{\text {th }}$ rule $A_{i}$ \\
\hline$\sigma_{\mathrm{i}}$ & Standard deviation of $\mathrm{i}^{\text {th }}$ rule \\
\hline$c_{i}$ & Mean of $i^{\text {th }}$ rule \\
\hline$w_{j}$ & Firing strength of $\mathrm{j}^{\mathrm{th}}$ node \\
\hline$\overline{\mathrm{w}_{\mathrm{j}}}$ & Normalisation of firing strength at $\mathrm{j}^{\text {th }}$ node \\
\hline $\mathrm{p}_{\mathrm{i}}, \mathrm{q}_{\mathrm{i}}, \mathrm{r}_{\mathrm{i}}$ & Consequent parameters \\
\hline
\end{tabular}




\begin{tabular}{|c|c|}
\hline$P_{\text {best }}$ & Personal best \\
\hline $\mathrm{G}_{\text {best }}$ & Global best \\
\hline $\mathrm{v}_{\mathrm{i}}(\mathrm{t})$ & Current velocity of particle \\
\hline $\mathrm{v}_{\mathrm{i}}(\mathrm{t}-1)$ & Previous velocity of particle \\
\hline $\mathrm{C}_{1}$ & Cognitive parameter \\
\hline $\mathrm{C}_{2}$ & Social parameter \\
\hline $\mathrm{r}_{1}, \mathrm{r}_{2}$ & Uniformly distributed numbers \\
\hline$\omega$ & Inertia weight \\
\hline$\omega_{\max }$ & Final inertia weight \\
\hline$\omega_{\min }$ & Initial inertia weight \\
\hline Itr $_{\max }$ & Maximum number of iteration \\
\hline Itr & Current iteration number \\
\hline$x_{i}(t-1)$ & Previous position of particle \\
\hline$x_{i}(t)$ & Current position of particle \\
\hline I & Light intensity of firefly \\
\hline $\mathrm{r}$ & Distance of firefly from light source \\
\hline $\mathrm{I}_{\mathrm{S}}$ & Intensity of light source \\
\hline$\beta$ & Attractiveness of firefly \\
\hline$\beta_{0}$ & Attractiveness of firefly at $r=0$ \\
\hline$\gamma$ & Coefficient of light \\
\hline $\mathrm{r}_{\mathrm{ij}}$ & Distance between firefly $x_{i}$ and firefly $x_{j}$ \\
\hline $\mathrm{d}$ & Dimension of search problem \\
\hline$\alpha$ & Randomization parameter \\
\hline rand & Random number \\
\hline Xmin & Minimum search range limit \\
\hline$X \max$ & Maximum search range limit \\
\hline nPop & Number of population \\
\hline $\mathrm{r}_{\mathrm{px}}$ & Distance between $P_{\text {best }}$ and population $x_{j}$ \\
\hline$r_{g x}$ & Distance between $G_{\text {best }}$ and population $x_{j}$ \\
\hline $\mathrm{I}_{\mathrm{f}}$ & Forecasted value \\
\hline $\mathrm{I}_{\mathrm{m}}$ & Actual value \\
\hline$\overline{\mathrm{I}_{\mathrm{m}}}$ & Mean of actual value \\
\hline$\overline{\mathrm{I}_{\mathrm{f}}}$ & Mean of forecasted value \\
\hline
\end{tabular}

\section{References}

1. Behera, M.K.; Majumder, I.; Nayak, N. Solar photovoltaic power forecasting using optimized modified extreme learning machine technique. Eng. Sci. Technol. Int. J. 2018, 21, 428-438. [CrossRef]

2. Semero, Y.K.; Zhang, J.; Zheng, D. North China Electric Power University PV power forecasting using an integrated GA-PSO-ANFIS approach and Gaussian process regression based feature selection strategy. CSEE J. Power Energy Syst. 2018, 4, 210-218. [CrossRef]

3. Zamo, M.; Mestre, O.; Arbogast, P.; Pannekoucke, O. A benchmark of statistical regression methods for short-term forecasting of photovoltaic electricity production, part I: Deterministic forecast of hourly production. Sol. Energy 2014, 105, 792-803. [CrossRef]

4. Rodríguez, F.; Fleetwood, A.; Galarza, A.; Fontan, L. Predicting solar energy generation through artificial neural networks using weather forecasts for microgrid control. Renew. Energy 2018, 126, 855-864. [CrossRef]

5. Eseye, A.T.; Zhang, J.; Zheng, D. Short-term photovoltaic solar power forecasting using a hybrid Wavelet-PSO-SVM model based on SCADA and Meteorological information. Renew. Energy 2018, 118, 357-367. [CrossRef]

6. Shi, J.; Lee, W.J.; Liu, Y.; Yang, Y.; Wang, P. Forecasting Power Output of Photovoltaic Systems Based on Weather Classification and Support Vector Machines. IEEE Trans. Ind. Appl. 2012, 48, 1064-1069. [CrossRef]

7. Huang, C.; Cao, L.; Peng, N.; Li, S.; Zhang, J.; Wang, L.; Luo, X.; Wang, J.H. Day-Ahead Forecasting of Hourly Photovoltaic Power Based on Robust Multilayer Perception. Sustainability 2018, 10, 4863. [CrossRef] 
8. Wang, J.; Ran, R.; Zhou, Y. A Short-Term Photovoltaic Power Prediction Model Based on an FOS-ELM Algorithm. Appl. Sci. 2017, 7, 423. [CrossRef]

9. Wang, J.; Li, P.; Ran, R.; Che, Y.; Zhou, Y. A Short-Term Photovoltaic Power Prediction Model Based on the Gradient Boost Decision Tree. Appl. Sci. 2018, 8, 689. [CrossRef]

10. Nandi, S.K.; Rahman, M.S.; Riadh, R.R. A Comparative Study on ANN Techniques in Predicting Solar Radiation for Various Meteorological Locations of Bangladesh. In Proceedings of the 2016 5th International Conference on Informatics, Electronics and Vision (ICIEV), Dhaka, Bangladesh, 13-14 May 2016; pp. 850-855.

11. Abuella, M.; Chowdhury, B. Solar Power Forecasting Using Artificial Neural Networks. In Proceedings of the 2015 North American Power Symposium (NAPS), Charlotte, NC, USA, 4-6 October 2015; pp. 1-5.

12. Awad, M.; Qasrawi, I. Enhanced RBF neural network model for time series prediction of solar cells panel depending on climate conditions (temperature and irradiance). Neural Comput. Appl. 2018, 30, 1757-1768. [CrossRef]

13. Li, Z.; Zhou, Y.; Cheng, C.; Li, Y.; Lai, K. Short Term Photovoltaic Power Generation Forecasting Using RBF Neural Network. In Proceedings of the 26th Chinese Control and Decision Conference (2014 CCDC), Changsha, China, 31 May-2 June 2014; pp. 2758-2763.

14. Olatomiwa, L.; Mekhilef, S.; Shamshirband, S.; Petković, D. Adaptive neuro-fuzzy approach for solar radiation prediction in Nigeria. Renew. Sustain. Energy Rev. 2015, 51, 1784-1791. [CrossRef]

15. Muhammad, A.; Gaya, M.; Aliyu, R.; Umar, I.D.; Yusuf, L.A.; Ali, M.U.; Khairi, M. Forecasting of global solar radiation using anfis and armax techniques. Proc. IOP Conf. Ser. Mater. Sci. Eng. 2018, 303, 012016. [CrossRef]

16. Sumithira, T.R.; Kumar, A.N. Prediction of monthly global solar radiation using adaptive neuro fuzzy inference system (ANFIS) technique over the State of Tamilnadu (India): A comparative study. Appl. Sol. Energy 2012, 48, 140-145. [CrossRef]

17. Ramli, M.A.; Twaha, S.; Al-Turki, Y.A. Investigating the performance of support vector machine and artificial neural networks in predicting solar radiation on a tilted surface: Saudi Arabia case study. Energy Convers. Manag. 2015, 105, 442-452. [CrossRef]

18. Ekici, B.B. A least squares support vector machine model for prediction of the next day solar insolation for effective use of PV systems. Measurement 2014, 50, 255-262. [CrossRef]

19. Zeng, J.; Qiao, W. Short-term solar power prediction using a support vector machine. Renew. Energy 2013, 52, 118-127. [CrossRef]

20. Mohandes, M.A. Modeling global solar radiation using Particle Swarm Optimization (PSO). Sol. Energy 2012, 86, 3137-3145. [CrossRef]

21. Ibrahim, I.A.; Khatib, T. A novel hybrid model for hourly global solar radiation prediction using random forests technique and firefly algorithm. Energy Convers. Manag. 2017, 138, 413-425. [CrossRef]

22. Olatomiwa, L.; Mekhilef, S.; Shamshirband, S.; Mohammadi, K.; Petković, D.; Sudheer, C. A support vector machine-firefly algorithm-based model for global solar radiation prediction. Sol. Energy 2015, 115, 632-644. [CrossRef]

23. Catalão, J.P.; Pousinho, H.; Mendes, V. Short-term wind power forecasting in Portugal by neural networks and wavelet transform. Renew. Energy 2011, 36, 1245-1251. [CrossRef]

24. Lyu, L.; Kantardzic, M.; Arabmakki, E. Solar Irradiance Forecasting by Using Wavelet Based Denoising. In Proceedings of the 2014 IEEE Symposium on Computational Intelligence for Engineering Solutions (CIES), Orlando, FL, USA, 9-12 December 2014; pp. 110-116.

25. Haque, A.U.; Mandal, P.; Nehrir, H.M.; Bhuiya, A.; Baker, R. A Hybrid Intelligent Framework for Wind Power Forecasting Engine. In Proceedings of the 2014 IEEE Electrical Power and Energy Conference, Calgary, AB, Canada, 12-14 November 2014; pp. 184-189.

26. Ramsami, P.; Oree, V. A hybrid method for forecasting the energy output of photovoltaic systems. Energy Convers. Manag. 2015, 95, 406-413. [CrossRef]

27. Agayev, N.; Aliyev, F. Solar Radiation Data Analysis In Baku By Using Daubechies Wavelets. Int. J. Innov. Sci. Math. 2015, 3, 163-167.

28. Cohen, R. Signal Denoising Using Wavelets; Project Report; Department of Electrical Engineering Technion, Israel Institute of Technology: Haifa, Israel, 2012.

29. Phootrakornchai, W.; Jiriwibhakorn, S. Online critical clearing time estimation using an adaptive neuro-fuzzy inference system (ANFIS). Int. J. Electr. Power Energy Syst. 2015, 73, 170-181. [CrossRef] 
30. Şahin, M.; Erol, R. A Comparative Study of Neural Networks and ANFIS for Forecasting Attendance Rate of Soccer Games. Math. Comput. Appl. 2017, 22, 43. [CrossRef]

31. Abdulshahed, A.M.; Longstaff, A.P.; Fletcher, S.; Myers, A. Thermal error modelling of machine tools based on ANFIS with fuzzy c-means clustering using a thermal imaging camera. Appl. Math. Model. 2015, 39, 1837-1852. [CrossRef]

32. Quej, V.H.; Almorox, J.; Arnaldo, J.A.; Saito, L. ANFIS, SVM and ANN soft-computing techniques to estimate daily global solar radiation in a warm sub-humid environment. Journal of Atmospheric and Solar-Terrestrial Physics 2017, 155, 62-70. [CrossRef]

33. Rahmani, R.; Yusof, R.; Seyedmahmoudian, M.; Mekhilef, S. Hybrid technique of ant colony and particle swarm optimization for short term wind energy forecasting. J. Wind Eng. Ind. Aerodyn. 2013, 123, 163-170. [CrossRef]

34. Semero, Y.K.; Zheng, D.; Zhang, J.A. PSO-ANFIS based Hybrid Approach for Short Term PV Power Prediction in Microgrids. Electr. Power Compon. Syst. 2018, 46, 95-103. [CrossRef]

35. Jallad, J.; Mekhilef, S.; Mokhlis, H.; Laghari, J.; Badran, O. Application of Hybrid Meta-Heuristic Techniques for Optimal Load Shedding Planning and Operation in an Islanded Distribution Network Integrated with Distributed Generation. Energies 2018, 11, 1134. [CrossRef]

36. Aydilek, I.B. A hybrid firefly and particle swarm optimization algorithm for computationally expensive numerical problems. Appl. Soft Comput. 2018, 66, 232-249. [CrossRef]

37. Fister, I.; Fister, I., Jr.; Yang, X.S.; Brest, J. A comprehensive review of firefly algorithms. Swarm Evol. Comput. 2013, 13, 34-46. [CrossRef]

38. Panda, M.R.; Dutta, S.; Pradhan, S. Hybridizing invasive weed optimization with firefly algorithm for multi-robot motion planning. Arab. J. Sci. Eng. 2018, 43, 4029-4039. [CrossRef]

39. Niknam, T.; Narimani, M.R.; Jabbari, M. Dynamic optimal power flow using hybrid particle swarm optimization and simulated annealing. Int. Trans. Electr. Energy Syst. 2013, 23, 975-1001. [CrossRef]

40. Premalatha, K.; Natarajan, A. Hybrid PSO and GA for global maximization. Int. J. Open Probl. Comput. Math 2009, 2, 597-608.

41. El Mghouchi, Y.; Chham, E.; Zemmouri, E.; El Bouardi, A. Assessment of different combinations of meteorological parameters for predicting daily global solar radiation using artificial neural networks. Build. Environ. 2019, 149, 607-622. [CrossRef]

42. Yona, A.; Senjyu, T.; Saber, A.Y.; Funabashi, T.; Sekine, H.; Kim, C.H. Application of Neural Network to one-day-ahead 24 Hours Generating Power Forecasting for Photovoltaic system. In Proceedings of the 2007 International Conference on Intelligent Systems Applications to Power Systems, Niigata, Japan, 5-8 November 2007; pp. 1-6.

43. Manikandan, N.; Subha, S. Software Design Challenges in Time Series Prediction Systems Using Parallel Implementation of Artificial Neural Networks. Sci. World J. 2016, 2016, 6709352. [CrossRef]

44. Fouilloy, A.; Voyant, C.; Notton, G.; Motte, F.; Paoli, C.; Nivet, M.-L.; Guillot, E.; Duchaud, J.L.; Jean-Laurent, D. Solar irradiation prediction with machine learning: Forecasting models selection method depending on weather variability. Energy 2018, 165, 620-629. [CrossRef]

(C) 2019 by the authors. Licensee MDPI, Basel, Switzerland. This article is an open access article distributed under the terms and conditions of the Creative Commons Attribution (CC BY) license (http://creativecommons.org/licenses/by/4.0/). 